\title{
Tuning Photosensitized Singlet Oxygen Generation Efficiency of Novel aza-BODIPY Dyes
}

\author{
Nagappanpillai Adarsh, Rekha R. Avirah, Danaboyina Ramaiah*
}

*To whom correspondence should be addressed at:

Photosciences and Photonics Division

National Institute for Interdisciplinary Science and Technology (NIIST)

CSIR, Trivandrum 695 019, INDIA.

Tel: +91 471 2515362. Fax: +914712490186

E-mail : $\underline{\text { rama@niist.res.in or d_ramaiah@ rediffmail.com }}$

S1. No:

No:

1 Experimental Section

$2 \quad$ Materials and methods

S4

3 Figures S1-S5 showing ${ }^{1}$ H NMR spectra of $\mathbf{3 a - b}, \mathbf{4 a - b}$ and $\mathbf{5 b}$.

S6

$4 \quad$ Figure S6 showing the absorption spectra of $\mathbf{3 a - b}$

S9

$5 \quad$ Figure $\mathrm{S} 7$ showing the emission spectra of $\mathbf{3 b}$

6 Figures S8-S10 showing the changes in the absorption spectra of DPBF

S10 upon irradiation in presence of $\mathbf{4 a}, \mathbf{4 b}$ and $\mathbf{M B}$, respectively.

7 Figure $\mathrm{S} 11$ showing the absorption spectra of $\mathbf{5 b}$ on continuous irradiation

8 Figure $\mathrm{S} 12$ showing the changes in the absorption spectra of DPBF upon $60 \mathrm{~s}$ irradiation in presence of $\mathbf{5 b}$ 


\section{Experimental Section}

\subsection{General Techniques}

The melting points were determined on a Mel-Temp II melting point apparatus. The IR spectra were recorded on a Perkin Elmer Model 882 infrared spectrometer. The electronic absorption spectra were recorded on a Shimadzu UV-3101 or 2401 PC UV-VIS-NIR scanning spectrophotometer. The fluorescence spectra were recorded on a SPEX-Fluorolog F112X

spectrofluorimeter. ${ }^{1} \mathrm{H}$ and ${ }^{13} \mathrm{C}$ NMR were recorded on a $500 \mathrm{MHz}$ Bruker advanced DPX spectrometer. All the solvents used were purified and distilled before use. Quantum yields of fluorescence were measured by the relative methods using optically dilute solutions. Nile blue $\left(\Phi_{\mathrm{em}}=0.52\right)$ in methanol was used as the standard. Solvents used were distilled and purified before use.

\subsection{Quantification of triplet state properties}

Nanosecond laser flash photolysis experiments were carried out by employing an Applied Photophysics model LKS-20 laser kinetic spectrometer using OCR-12 Series Quanta Ray Nd:YAG laser. The analyzing and laser beams were fixed at right angles to each other. The laser energy was $64 \mathrm{~mJ}$ at $355 \mathrm{~nm}$. The triplet yields $\left(\Phi_{\mathrm{T}}\right)$ of the aza-BODIPY derivatives were measured employing an earlier described method of energy transfer to $\beta$-carotene using $\mathrm{Ru}(\mathrm{bpy})_{3}{ }^{2+}$, as the reference. For these experiments, Ru(bpy $)_{3}{ }^{2+}$ and the aza-BODIPY derivatives, optically matched at $355 \mathrm{~nm}$, were mixed with a known volume of $\beta$-carotene solution (end concentration of $\beta$-carotene was $\left.2.0 \times 10^{4} \mathrm{M}\right)$. The transient absorbance $(\Delta \mathrm{A})$ of the $\beta$-carotene triplet, formed by the energy transfer from $\mathrm{Ru}(\mathrm{bpy})_{3}{ }^{2+}$ or the aza-BODIPY triplet, was monitored at $510 \mathrm{~nm}$. Comparison of plateau absorbance following the completion of sensitized triplet formation, properly corrected for the decay of the donor triplets in competition with energy transfer to $\beta$-carotene, enabled us to estimate $\Phi_{\mathrm{T}}$ of BODIPY derivatives based on eq. 1 ,

$$
\Phi_{\mathrm{T}}^{\mathrm{bod}}=\Phi_{\mathrm{T}}^{\mathrm{ref}} \frac{\Delta \mathrm{A}_{\text {bod }}}{\Delta \mathrm{A}_{\text {ref }}} \frac{\mathrm{k}_{\mathrm{obs}}^{\mathrm{bod}}}{\mathrm{k}_{\mathrm{obs}}^{\mathrm{bod}}-\mathrm{k}_{0}^{\mathrm{bod}}} \frac{\mathrm{k}_{\mathrm{obs}}^{\mathrm{ref}}-\mathrm{k}_{0}^{\mathrm{ref}}}{\mathrm{k}_{\mathrm{obs}}^{\mathrm{ref}}}
$$

where superscripts 'bod' and 'ref' designate the different aza-BODIPY derivatives and $\mathrm{Ru}(\mathrm{bpy})_{3}{ }^{2+}$, respectively, $\mathrm{k}_{\mathrm{obs}}$, is the pseudo-first-order rate constant for the growth of the $\beta$ carotene triplet and $\mathrm{k}_{0}$ is the rate constant for the decay of the donor triplets, in the absence of $\beta$ - 
carotene, observed in solutions containing $\mathrm{Ru}(\mathrm{bpy})_{3}{ }^{2+}$ or aza-BODIPY dye at the same optical density (OD) as those used for sensitization. The direct excitation of $\beta$-carotene did not result in any significant triplet formation under these experimental conditions, because of negligible triplet yield. The $\Phi_{\mathrm{T}}^{\text {ref }}$ in methanol for $\mathrm{Ru}(\mathrm{bpy})_{3}{ }^{2+}$ was taken to be unity. The $\Phi_{\mathrm{T}}$ data obtained in this manner are reliable to the extent to which the assumption regarding $100 \%$ efficiency of energy transfer to $\beta$-carotene is valid.

\subsection{Quantification of singlet oxygen generation}

Singlet oxygen generation studies were carried out with a light source $200 \mathrm{~W}$ xenon lamp (model 3767) on an Oriel optical bench (model 11200) with a grating monochromator (model 77250). The intensity of light was maintained constant throughout the irradiations by measuring the output using an Oriel photodiode detection system (model 7072). Quantum yields for singlet oxygen generation in DMSO were determined by monitoring the photooxidation of DPBF sensitized by the aza-BODIPY derivatives. DPBF is a convenient acceptor because it absorbs in a region of dye transparency and rapidly scavenges singlet oxygen to give colorless products. This reaction occurs with little or no physical quenching. Singlet oxygen quantum yields were measured at low dye concentrations (optical density 0.2-0.3 at the irradiation wavelengths $>630$ $\mathrm{nm}$ ) to minimize the possibility of singlet oxygen quenching by the dyes. The photooxidation of DPBF was monitored between $2 \mathrm{~s}$ to 2 min. depending on the efficiency of the dye sensitizer. No thermal recovery of DPBF (from a possible decomposition of endoperoxide product) was observed under the conditions of these experiments. The quantum yields of singlet oxygen generation $\left(\Phi\left[{ }^{1} \mathrm{O}_{2}\right]\right)$ were calculated by a relative method using optically matched solutions and comparing the quantum yield of photooxidation of DPBF sensitized by the dye of interest to the quantum yield of $\mathrm{MB}\left(\Phi\left[{ }^{1} \mathrm{O}_{2}\right]=0.52\right)$ sensitized DPBF photooxidation as the reference. The following eq. 2 was used,

$$
\left.\Phi\left({ }^{1} \mathrm{O}_{2}\right){ }^{\text {bod }}=\Phi\left({ }^{1} \mathrm{O}_{2}\right)\right)^{\mathrm{MB}} \frac{\mathrm{m}^{\text {bod }} \mathrm{F}^{\mathrm{MB}}}{\mathrm{m}^{\mathrm{MB}} \mathrm{F}^{\text {bod }}}
$$

where superscripts 'bod' and 'MB' designate aza-BODIPY derivatives and MB, respectively, $\Phi\left[{ }^{1} \mathrm{O}_{2}\right]$ is the quantum yield of singlet oxygen, $\mathrm{m}$ is the slope of a plot of difference in change in absorbance of DPBF (at $418 \mathrm{~nm}$ ) with the irradiation time and $\mathrm{F}$ is the absorption correction factor, which is given by $\mathrm{F}=1-10^{-\mathrm{OD}}$ ( $\mathrm{OD}$ at the irradiation wavelength). 


\section{Materials and Methods}

Starting materials. 3,5-dimethoxy benzaldehyde, 4-bromo acetophenone, 4-iodo acetophenone, nitromethane, diethylamine, ammonium acetate, borontrifluoride diethyletherate, triethylamine, $\mathrm{N}$-iodosuccinimide, methylene blue, $\beta$-carotene were purchased from Aldrich and S. D. Fine Chemicals, India. 1,3-diphenylisobenzofuran (DPBF) was recrystallized from a mixture (1: 1) of ethanol and chloroform. 4-bromophenyl-3-(3,5-dimethoxyphenyl)prop-2-n-1one (1a), mp 86-88 ${ }^{\circ} \mathrm{C}$, 3-(3,5-dimehoxyphenyl)-1-phenylprop-2-en-1-one (1b), mp 80-82 ${ }^{\circ} \mathrm{C}$ were synthesized by modifying the reported procedures. ${ }^{1}$

\subsection{General procedure for the synthesis of $2 a-b$}

To a solution of 1a-b ( $2 \mathrm{~g}, 5.76 \mathrm{mmol})$ dissolved in $80 \mathrm{~mL}$ of methanol was added diethyl amine $(4 \mathrm{~mL})$ and nitromethane $(2 \mathrm{~mL})$ and refluxed for $24 \mathrm{~h}$. The mixture was neutralized using $1 \mathrm{~N} \mathrm{HCl}$ and extracted with chloroform. The removal of the solvent gave a residue which was separated by column chromatography over silica gel. Elution of the column with a mixture (1:9) of ethyl acetate and hexane gave $\mathbf{2 a - b}$ in good yields.

2a: $75 \%$, IR (KBr) $v_{\max } 1680,1562,1280 \mathrm{~cm}^{-1} ;{ }^{1} \mathrm{H}-\mathrm{NMR}\left(\mathrm{CDCl}_{3}, 500 \mathrm{MHz}\right) \delta 7.88(2 \mathrm{H}$, d, J = 8.5 Hz), $7.73(2 \mathrm{H}, \mathrm{d}, \mathrm{J}=8.5 \mathrm{~Hz}), 7.70(1 \mathrm{H}, \mathrm{s}), 7.41(1 \mathrm{H}, \mathrm{s}), 6.77(2 \mathrm{H}, \mathrm{s}), 4.20(1 \mathrm{H}, \mathrm{s}), 4.11$ $(1 \mathrm{H}, \mathrm{s}), 4.05(1 \mathrm{H}, \mathrm{t}), 3.84(6 \mathrm{H}, \mathrm{s}), 3.05(2 \mathrm{H}, \mathrm{s}) ;{ }^{13} \mathrm{C} \mathrm{NMR}\left(\mathrm{CDCl}_{3}, 125 \mathrm{MHz}\right) \delta 161.1,145.4$, 137.9, 137.4, 136.5, 129.9, 122.0, 106.4, 102.9, 100.6, 55.5; FAB-MS m/z Cald for $\mathrm{C}_{18} \mathrm{H}_{19} \mathrm{NO}_{5}$ 329.352, Found 329.357.

2b: $78 \%$, IR (KBr) $v_{\max } 1683,1595,1298,1205 \mathrm{~cm}^{-1} ;{ }^{1} \mathrm{H}-\mathrm{NMR}\left(\mathrm{CDCl}_{3}, 500 \mathrm{MHz}\right) \delta$ $7.67(2 \mathrm{H}, \mathrm{d}, \mathrm{J}=8.5 \mathrm{~Hz}), 7.49(2 \mathrm{H}, \mathrm{d}, \mathrm{J}=8.5 \mathrm{~Hz}), 6.31(2 \mathrm{H}, \mathrm{s}), 6.25(1 \mathrm{H}, \mathrm{s}), 4.70(1 \mathrm{H}, \mathrm{t}), 4.58$ $(1 \mathrm{H}, \mathrm{s}), 4.05(1 \mathrm{H}, \mathrm{t}), 3.66(6 \mathrm{H}, \mathrm{s}), 3.35(2 \mathrm{H}, \mathrm{q}) ;{ }^{13} \mathrm{C} \mathrm{NMR}\left(\mathrm{CDCl}_{3}, 125 \mathrm{MHz}\right) \delta 194.8,160.1$, 140.3, 134.0, 130.9, 128.4, 127.7, 104.6, 98.1, 78.3, 54.2, 40.3, 38.3; FAB-MS m/z Cald for $\mathrm{C}_{18} \mathrm{H}_{18} \mathrm{BrNO}_{5}$ 408.241, Found 408.239.

\subsection{General procedure for the synthesis of 3a-b}

The nitromethene derivatives $\mathbf{2 a - b}(1 \mathrm{~g}, 2.45 \mathrm{mmol})$ and ammonium acetate $(7.6 \mathrm{~g}, 95$ mmol) were dissolved in ethanol $(20 \mathrm{~mL})$ and heated under reflux for $48 \mathrm{~h}$. The precipitated product was filtered, washed with cold ethanol, dried and recrystallized from chloroform to give $\mathbf{3 a - b}$ as a violet compounds. 
3a: 40\%, mp 220-221 ${ }^{\circ} \mathrm{C}$; IR (KBr) $v_{\max } 3062,1597,1537,1348 \mathrm{~cm}^{-1} ;{ }^{1} \mathrm{H}-\mathrm{NMR}\left(\mathrm{CDCl}_{3}\right.$, $500 \mathrm{MHz}) \delta 7.97(4 \mathrm{H}, \mathrm{d}, \mathrm{J}=8 \mathrm{~Hz}), 7.62(2 \mathrm{H}, \mathrm{d}, \mathrm{J}=8 \mathrm{~Hz}), 7.56(6 \mathrm{H}, \mathrm{d}, \mathrm{J}=7 \mathrm{~Hz}), 7.49(2 \mathrm{H}, \mathrm{d}, \mathrm{J}$ $=7 \mathrm{~Hz}), 7.11(2 \mathrm{H}, \mathrm{s}), 6.94(2 \mathrm{H}, \mathrm{d}, \mathrm{J}=8.5 \mathrm{~Hz}), 3.95(6 \mathrm{H}, \mathrm{s}), 3.76(6 \mathrm{H}, \mathrm{s}) ;{ }^{13} \mathrm{C} \mathrm{NMR}_{\left(\mathrm{CDCl}_{3}, 125\right.}$ MHz) $\delta 154.8,149.5,149.3,148.8,142.7,132.2,129.9,129.1$, 127.0, 126.5, 121.9, 114.0, 112.3, 111.0, 56.0, 55.8; FAB-MS m/z Cald for $\mathrm{C}_{36} \mathrm{H}_{31} \mathrm{~N}_{3} \mathrm{O}_{4}$ 570.231, Found 570.232.

3b: 50\%, mp 245-246 ${ }^{\circ} \mathrm{C}$; IR (KBr) $v_{\max } 2999,1589,1456,1338,1278 \mathrm{~cm}^{-1}$; ${ }^{1} \mathrm{H}-\mathrm{NMR}$ $\left(\mathrm{CDCl}_{3}, 500 \mathrm{MHz}\right) \delta 7.77(4 \mathrm{H}, \mathrm{d}, \mathrm{J}=8.5 \mathrm{~Hz}), 7.67(4 \mathrm{H}, \mathrm{d}, \mathrm{J}=8.5 \mathrm{~Hz}), 7.10(2 \mathrm{H}, \mathrm{s}), 7.08(4 \mathrm{H}$, m), $6.48(2 \mathrm{H}, \mathrm{t}), 3.69(12 \mathrm{H}, \mathrm{s}) ;{ }^{13} \mathrm{C} \mathrm{NMR}\left(\mathrm{CDCl}_{3}, 125 \mathrm{MHz}\right) \delta 161.4,160.6,156.4,154.0$, 149.7, 143.3, 140.8, 138.1, 135.2, 132.4, 131.8, 130.9, 128.6, 127.8, 124.5, 123.6, 117.22, 115.5, 106.9, 105.5, 100.9, 100.6, 55.5; FAB-MS m/z Cald for $\mathrm{C}_{36} \mathrm{H}_{29} \mathrm{Br}_{2} \mathrm{~N}_{3} \mathrm{O}_{4}$ 727.442, Found 727.453 $(\mathrm{M}+1)^{+}$.

\subsection{General procedure for the synthesis of $4 a-b$}

Compounds 3a-b $(0.45 \mathrm{mmol})$ dissolved in dry toluene $(80 \mathrm{~mL})$ was treated with triethylamine $(0.8 \mathrm{~mL}, 4.6 \mathrm{mmol})$ and stirred for $10 \mathrm{~min}$ at $30^{\circ} \mathrm{C}$. To this reaction mixture, boron trifluoride diethyl etherate $(1 \mathrm{~mL}, 8.13 \mathrm{mmol})$ was added and heated at $80{ }^{\circ} \mathrm{C}$ for $4 \mathrm{~h}$. The solvent was evaporated, washed with water $(2 \times 50 \mathrm{~mL})$ and extracted with chloroform. Removal of the solvent gave a residue, which was separated by column chromatography over silica gel. Elution of the column with a mixture (1:1) dichloromethane and hexane gave the products $\mathbf{4 a - b}$ as a metallic brown solids.

4a: 75\%, mp 239-240 ${ }^{\circ} \mathrm{C}$; IR (KBr) $v_{\max } 1595,1500,1452,1267,1122 \mathrm{~cm}^{-1}$; ${ }^{1} \mathrm{H}-\mathrm{NMR}$ $\left(\mathrm{CDCl}_{3}, 500 \mathrm{MHz}\right) \delta 8.09(4 \mathrm{H}, \mathrm{s}), 7.85(2 \mathrm{H}, \mathrm{q}, \mathrm{J}=8.5 \mathrm{~Hz}), 7.67(2 \mathrm{H}, \mathrm{s}), 7.57(6 \mathrm{H}, \mathrm{s}), 7.50(2 \mathrm{H}$, s), $7.14(2 \mathrm{H}, \mathrm{d}, \mathrm{J}=8.5 \mathrm{~Hz}), 3.87(6 \mathrm{H}, \mathrm{s}), 3.78(6 \mathrm{H}, \mathrm{s}) ;{ }^{13} \mathrm{C} \mathrm{NMR}\left(\mathrm{CDCl}_{3}, 125 \mathrm{MHz}\right) \delta 158.1$, 150.8, 148.9, 144.7, 143.5, 131.1, 130.9, 129.3, 128.5, 124.7, 122.9, 118.9, 112.5, 55.7, 55.6; FAB-MS m/z Cald for $\mathrm{C}_{36} \mathrm{H}_{30} \mathrm{BF}_{2} \mathrm{~N}_{3} \mathrm{O}_{4}$ 617.458, Found 617.456.

4b: $80 \%$, mp 284-285 ${ }^{\circ} \mathrm{C}$; IR (KBr) vmax $1587,1473,1398,1261 \mathrm{~cm}^{-1} ;{ }^{1} \mathrm{H}$ NMR $\left(\mathrm{CDCl}_{3}\right.$, $500 \mathrm{MHz}) \delta 7.90(4 \mathrm{H}, \mathrm{d}, \mathrm{J}=8.5 \mathrm{~Hz}), 7.63(4 \mathrm{H}, \mathrm{d}, \mathrm{J}=8.5 \mathrm{~Hz}), 7.12(4 \mathrm{H}, \mathrm{s}), 6.96(2 \mathrm{H}, \mathrm{s}), 6.54$ $(2 \mathrm{H}, \mathrm{s}), 3.76(12 \mathrm{H}, \mathrm{s}) ;{ }^{13} \mathrm{C} \mathrm{NMR}\left(\mathrm{CDCl}_{3}, 125 \mathrm{MHz}\right) \delta 160.8,158.2,145.7,144.9,133.8,132.0$, 131.0, 130.2, 126.0, 119.6, 107.3, 102.3, 99.9, 55.5; FAB-MS m/z Cald for $\mathrm{C}_{36} \mathrm{H}_{28} \mathrm{BBr}_{2} \mathrm{~F}_{2} \mathrm{~N}_{3} \mathrm{O}_{4}$ 775.243, Found 775.244. 


\subsection{Procedure for the synthesis of $5 \mathrm{~b}$}

To a solution of $\mathbf{4 b}(0.2 \mathrm{~g}, 0.26 \mathrm{mmol})$ in $40 \mathrm{~mL}$ mixture (3:1) of chloroform and acetic acid, $N$-iodo succinimide (260 mg, $1.16 \mathrm{mmol}$ ) was added and stirred at $30{ }^{\circ} \mathrm{C}$ for $10 \mathrm{~h}$. The reaction mixture was washed with sodium thiosulphate followed by sodium bicarbonate solution and extracted with chloroform. Removal of the solvent gave a residue which was separated by column chromatography over silica gel. Elution of the column with a mixture (1:9) of methanol and chloroform gave $65 \%$ of $\mathbf{5 b}$, mp 308-310 ${ }^{\circ} \mathrm{C}$; IR (KBr) $v_{\max } 1587,1506,1477,1336,1278 \mathrm{~cm}^{-1}$; ${ }^{1} \mathrm{H} \mathrm{NMR}\left(\mathrm{CDCl}_{3}, 500 \mathrm{MHz}\right) \delta 7.93(3 \mathrm{H}, \mathrm{d}, \mathrm{J}=8.5 \mathrm{~Hz}), 7.63(5 \mathrm{H}, \mathrm{d}, \mathrm{J}=11.5 \mathrm{~Hz}), 6.64(1 \mathrm{H}, \mathrm{s})$, $6.37(2 \mathrm{H}, \mathrm{s}), 5.30(1 \mathrm{H}, \mathrm{s}), 3.89(12 \mathrm{H}, \mathrm{s}) ;{ }^{13} \mathrm{C} \mathrm{NMR}\left(\mathrm{CDCl}_{3}, 125 \mathrm{MHz}\right) \delta 159.0,157.9,153.0$, 144.3, 142.7, 132.0, 129.5, 125.6, 80.2, 56.9; HRMS $\left(\mathrm{EI}^{+}\right) \mathrm{m} / \mathrm{z}$ Cald for $\mathrm{C}_{36} \mathrm{H}_{24} \mathrm{BBr}_{2} \mathrm{~F}_{2} \mathrm{I}_{4} \mathrm{~N}_{3} \mathrm{O}_{4}$ 1279.642, Found $1279.628[\mathrm{M}+1]^{+}$.

\section{Reference}

1. Kumar, C. V.; Ramaiah, D.; Das, P. K.; George, M. V. J. Org. Chem. 1985, 50, 28182825.

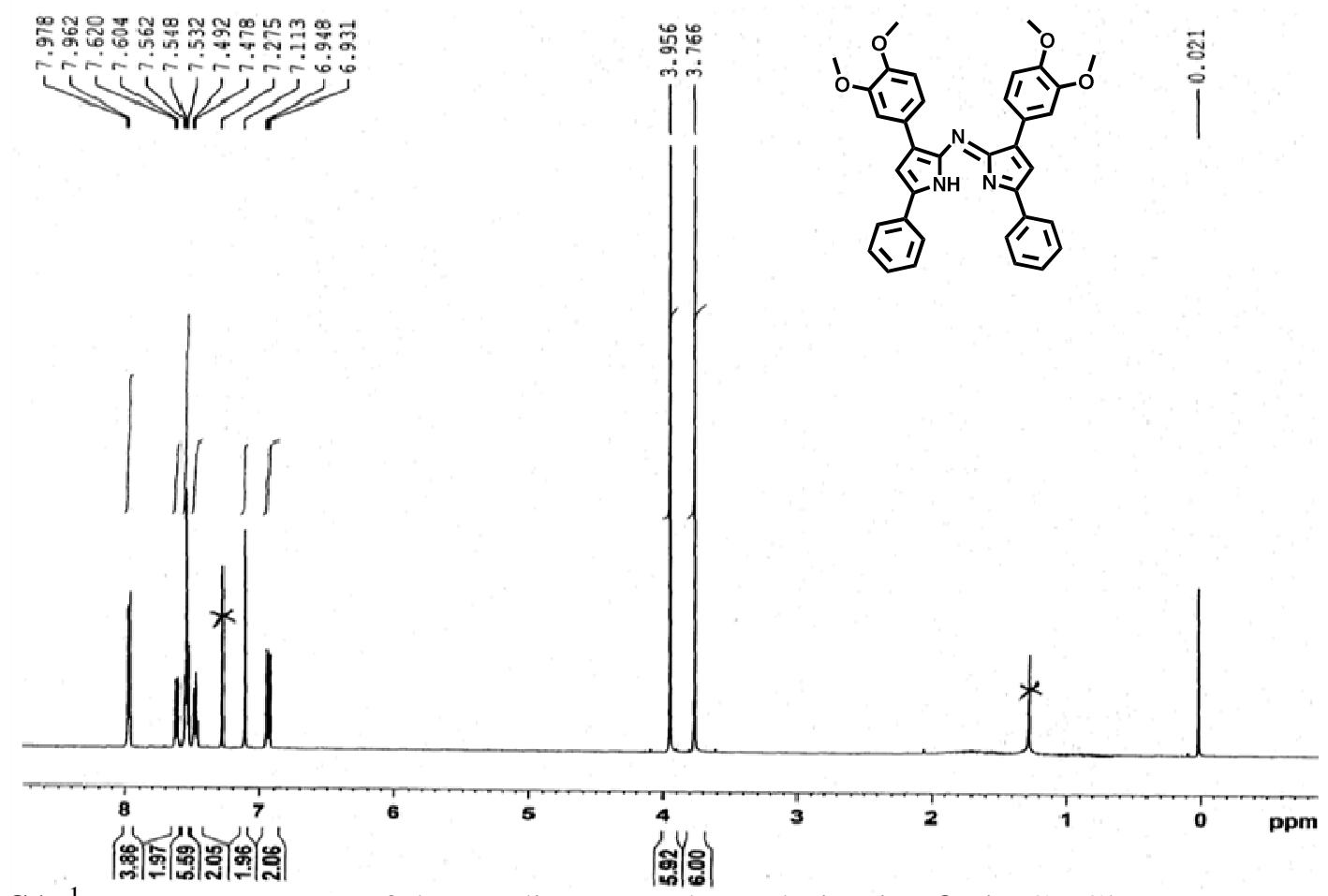

Figure S1. ${ }^{1} \mathrm{HNMR}$ spectrum of the azadipyrromethene derivative $3 \mathbf{a}$ in $\mathrm{CDCl}_{3}$. 


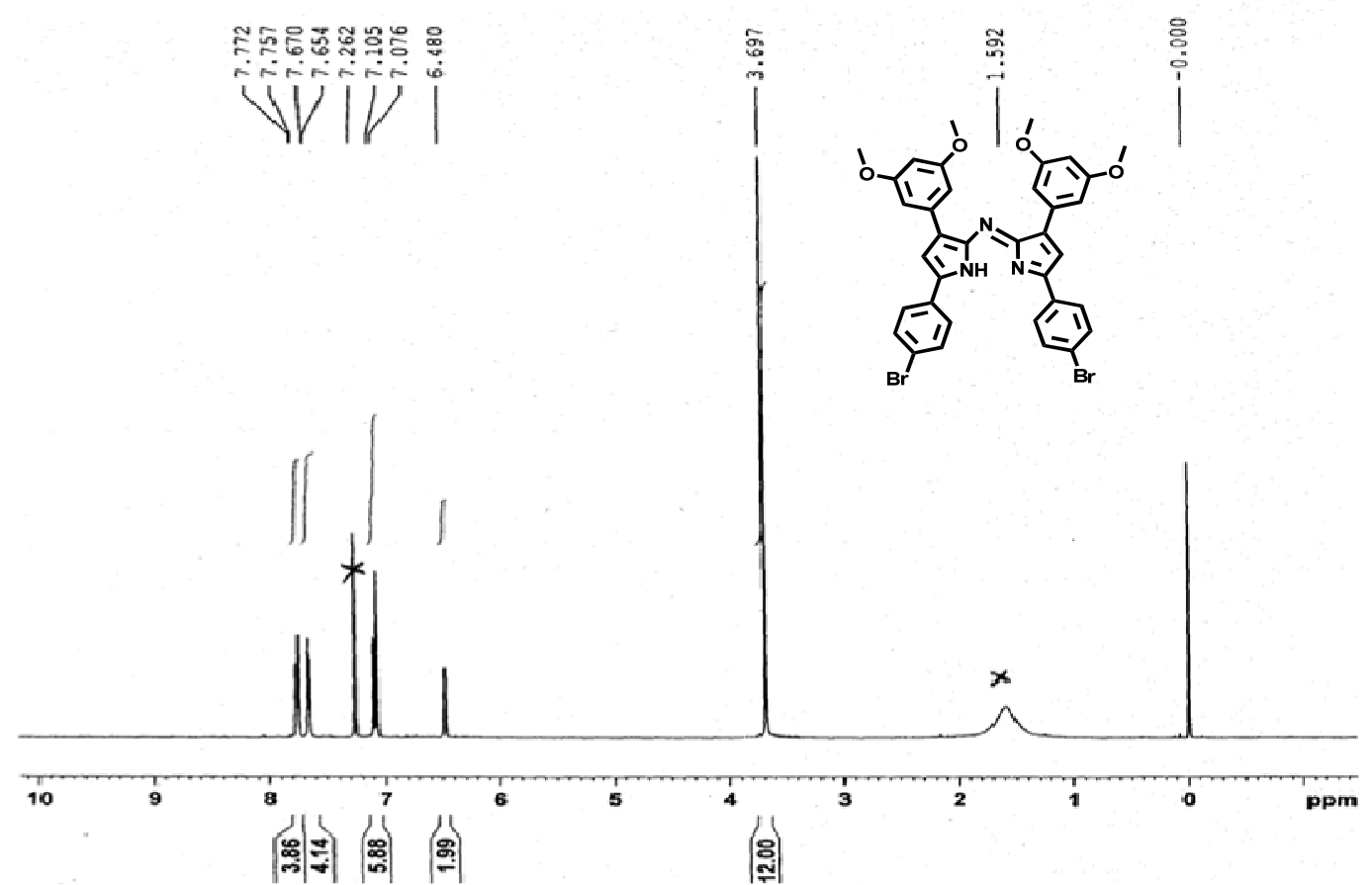

Figure S2. ${ }^{1} \mathrm{HNMR}$ spectrum of the azadipyrromethene derivative $\mathbf{3 b}$ in $\mathrm{CDCl}_{3}$.

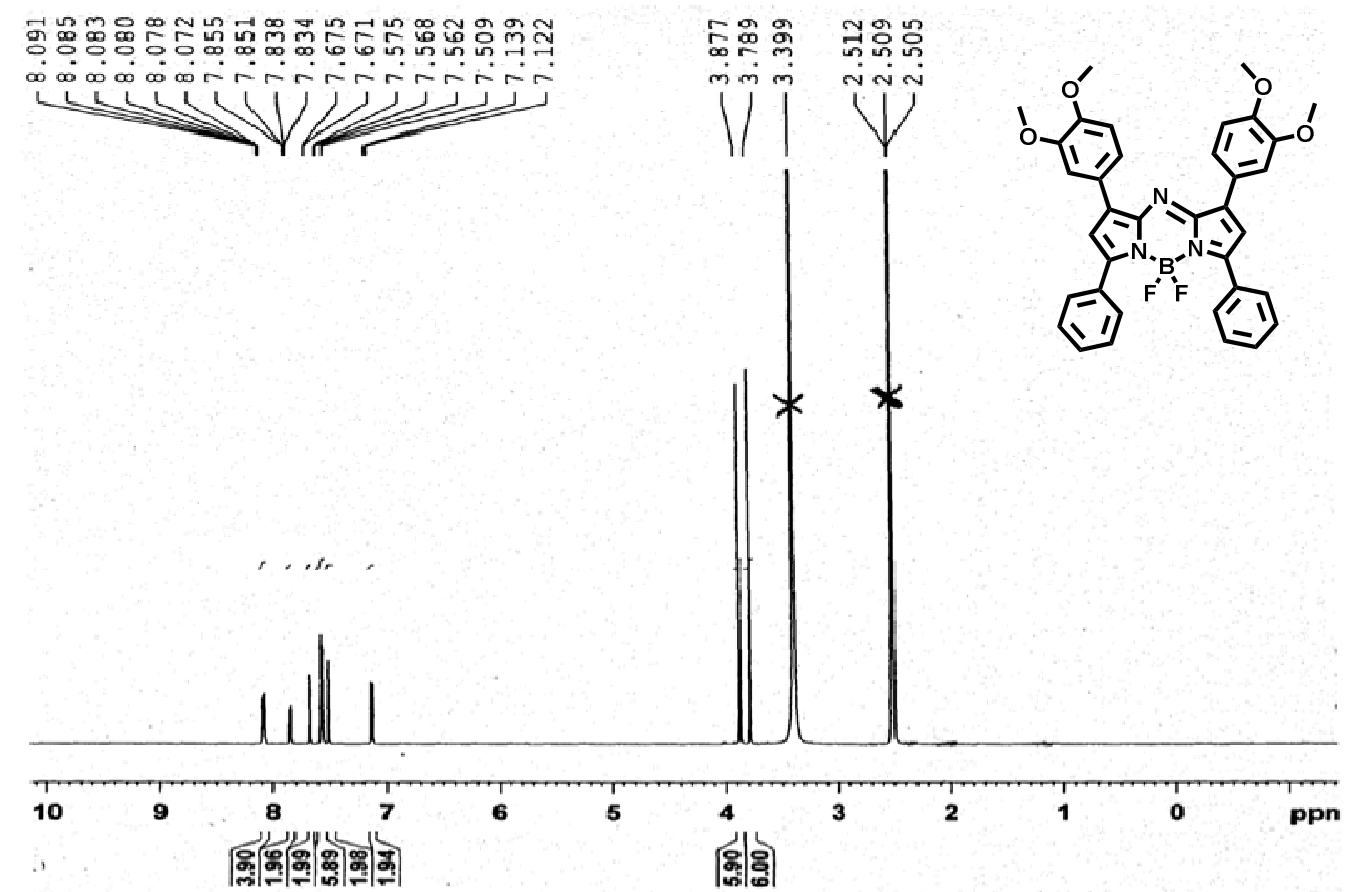

Figure S3. ${ }^{1} \mathrm{HNMR}$ spectrum of the BODIPY derivative 4a in DMSO- $d 6$. 


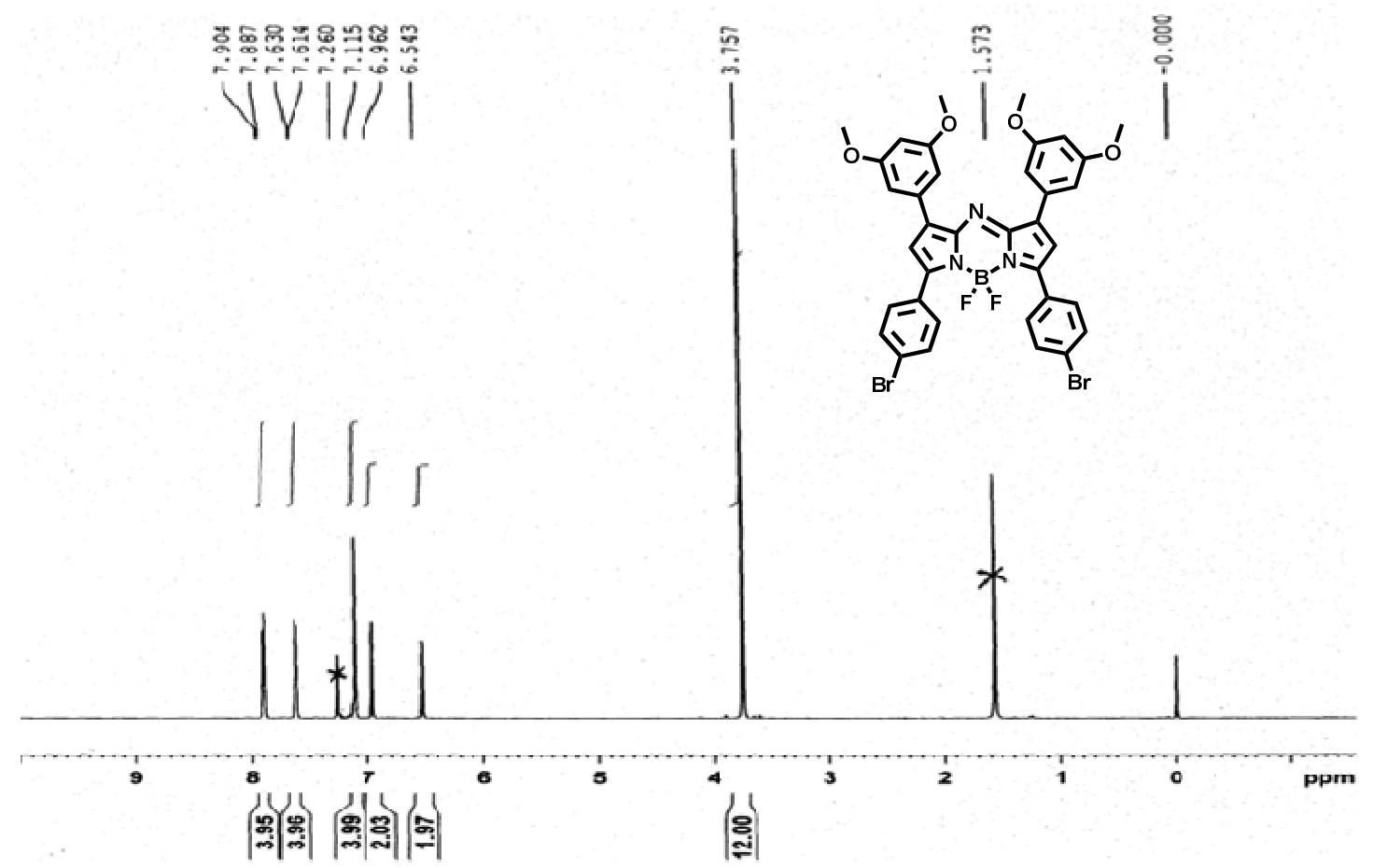

Figure S4. ${ }^{1} \mathrm{HNMR}$ spectrum of the BODIPY derivative $\mathbf{4 b}$ in $\mathrm{CDCl}_{3}$.

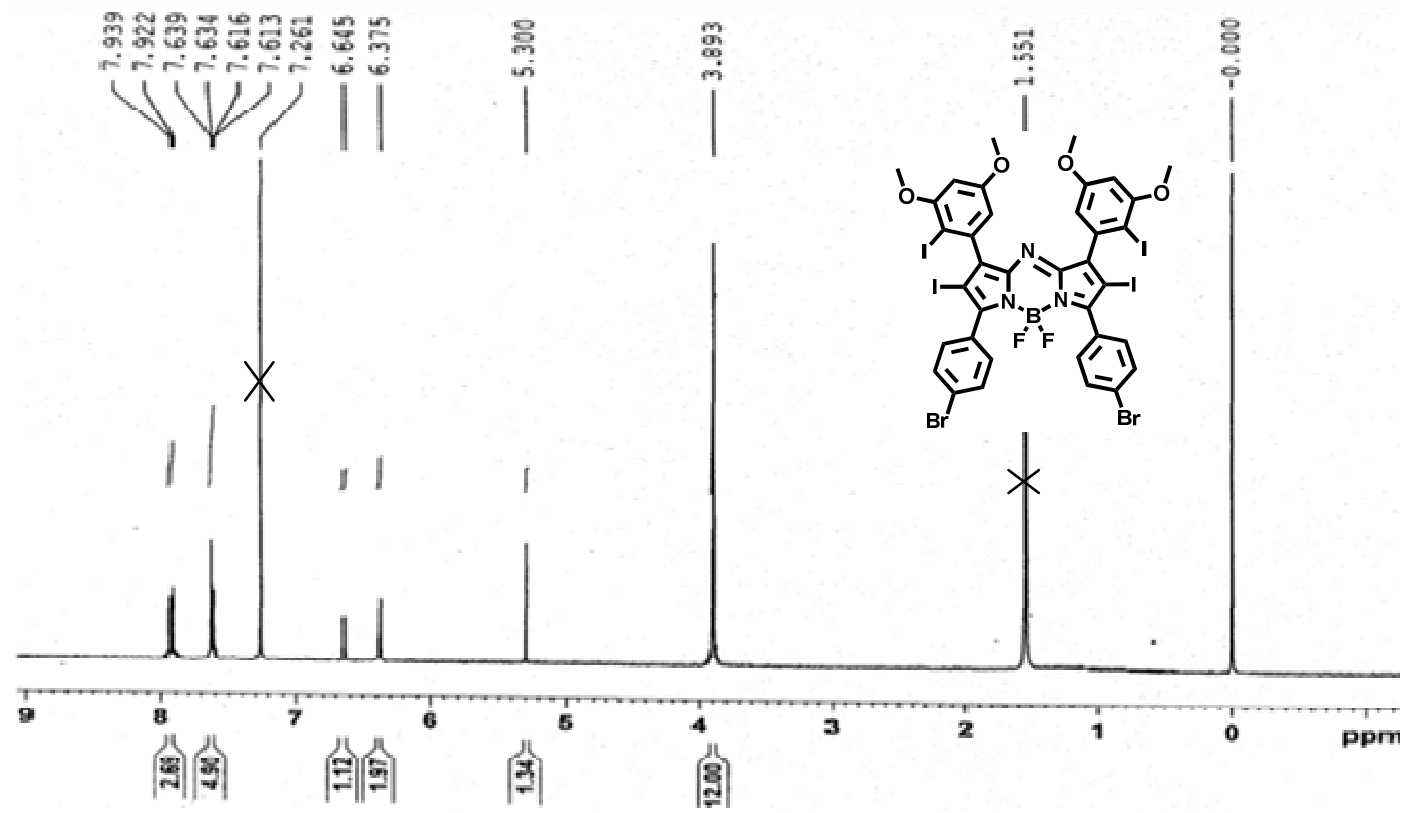

Figure S5. ${ }^{1} \mathrm{HNMR}$ spectrum of the BODIPY derivative $\mathbf{5 b}$ in $\mathrm{CDCl}_{3}$. 


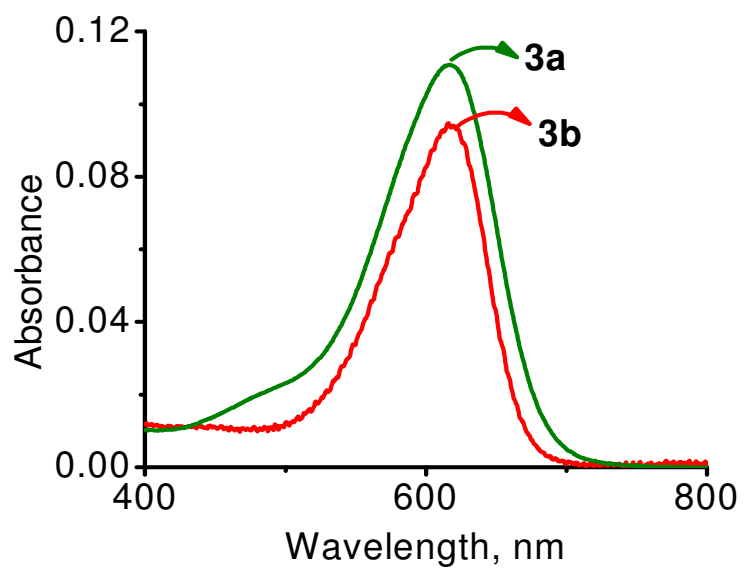

Figure S6. Absorption spectra of 3a-b.

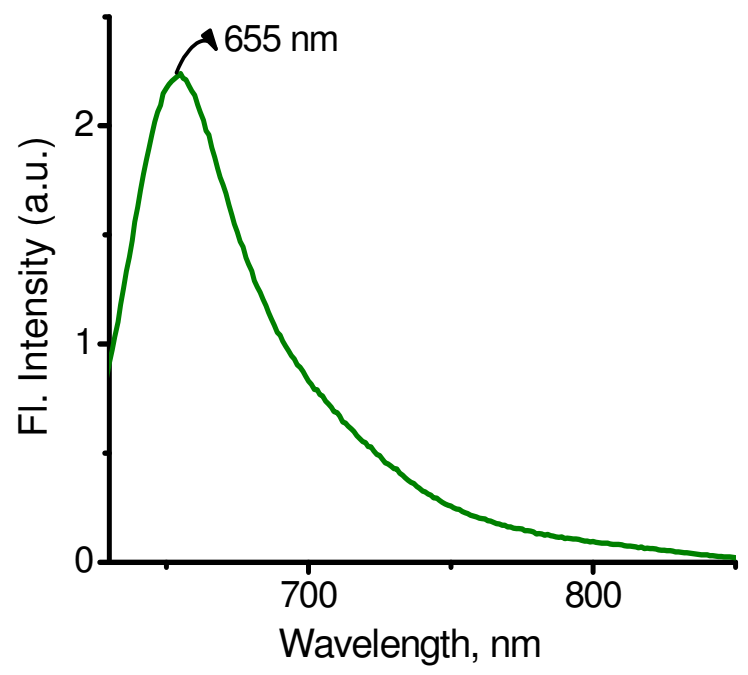

Figure S7. Emission spectrum of 3b. Excitation wavelength, $630 \mathrm{~nm}$. 


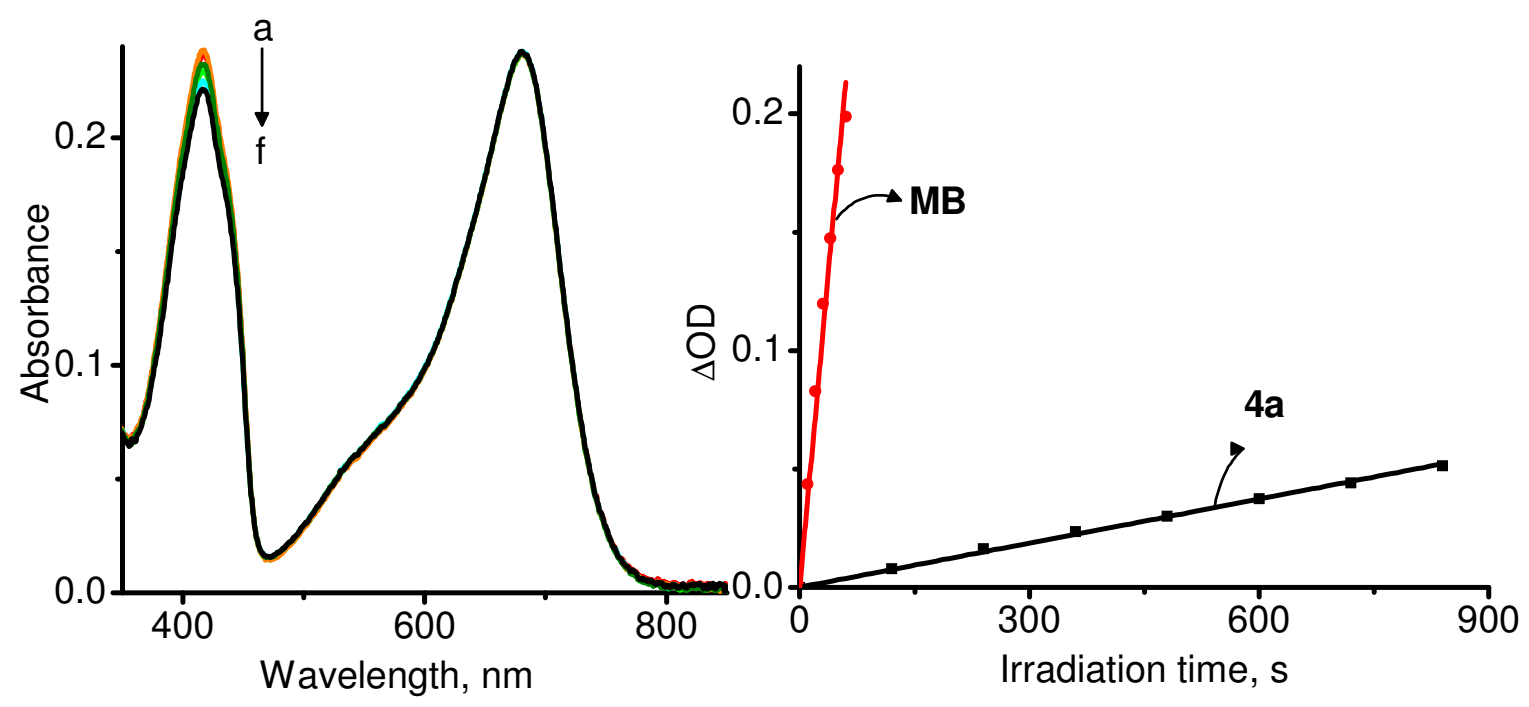

Figure S8. (A) Changes in the absorption spectrum of DPBF upon irradiation in the presence of 4a. a) 0 and f) $600 \mathrm{~s}$ (recorded at $120 \mathrm{~s}$ interval). (B) Plot of change in absorbance of DPBF at $418 \mathrm{~nm}$ vs irradiation time $\left(\lambda_{\text {irr }}=630 \mathrm{~nm}\right)$ in the presence of $\mathbf{4 a}$ against methylene blue $(\mathbf{M B})$ as the standard.

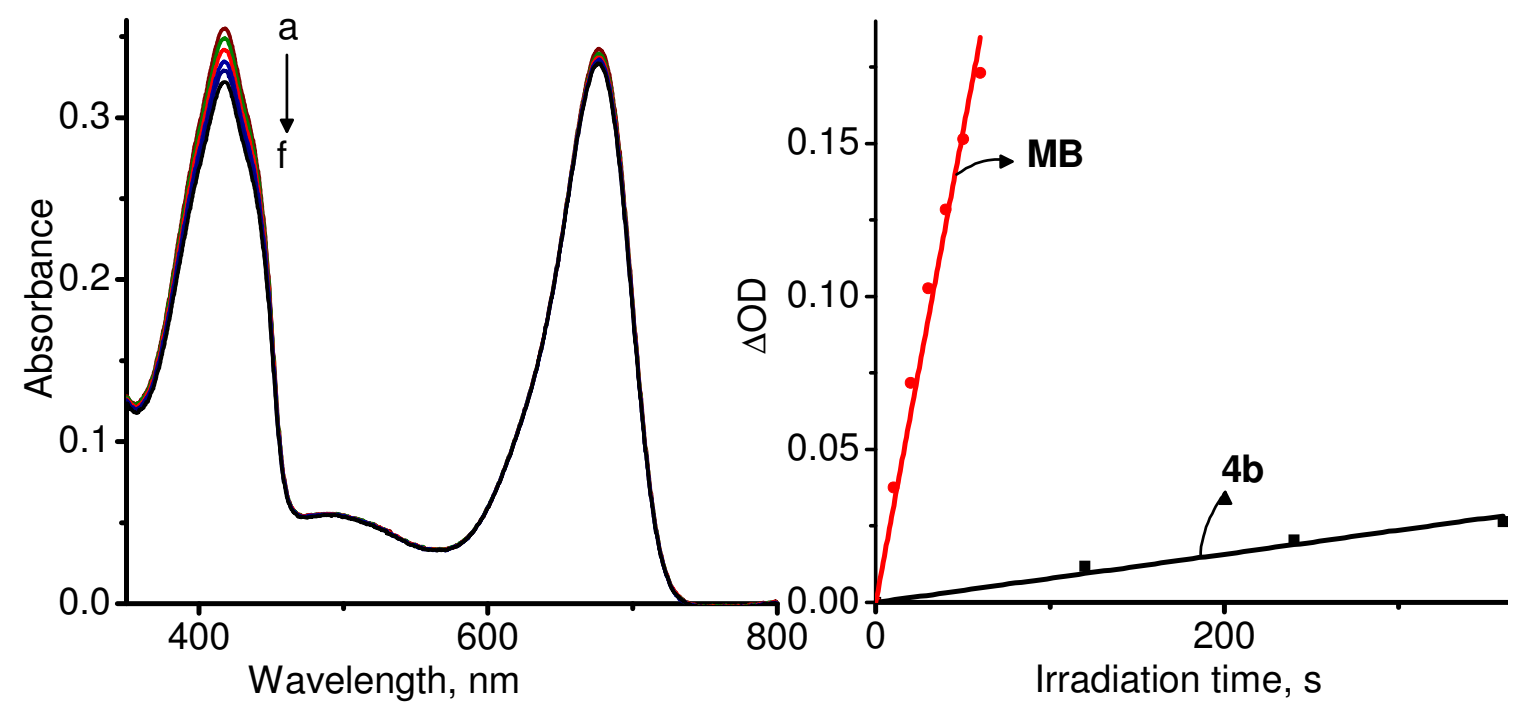

Figure S9. (A) Changes in the absorption spectrum of DPBF upon irradiation in the presence of 4b. a) 0 and f) $360 \mathrm{~s}$ (recorded at $60 \mathrm{~s}$ interval). (B) Plot of change in absorbance of DPBF at 418 $\mathrm{nm}$ vs irradiation time $\left(\lambda_{\text {irr }}=630 \mathrm{~nm}\right)$ in the presence of $\mathbf{4 b}$ against methylene blue $(\mathbf{M B})$ as the standard. 


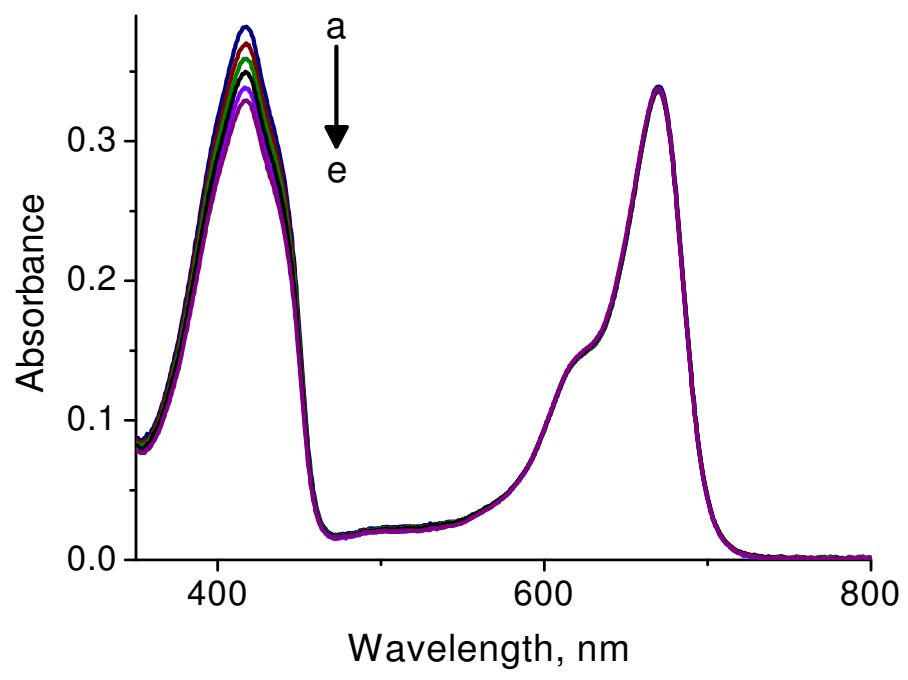

Figure S10. Changes in the absorption spectrum of DPBF upon irradiation in the presence of methylene blue (MB). a) 0 and e) $10 \mathrm{~s}$ (recorded at every $2 \mathrm{~s}$ intervals).

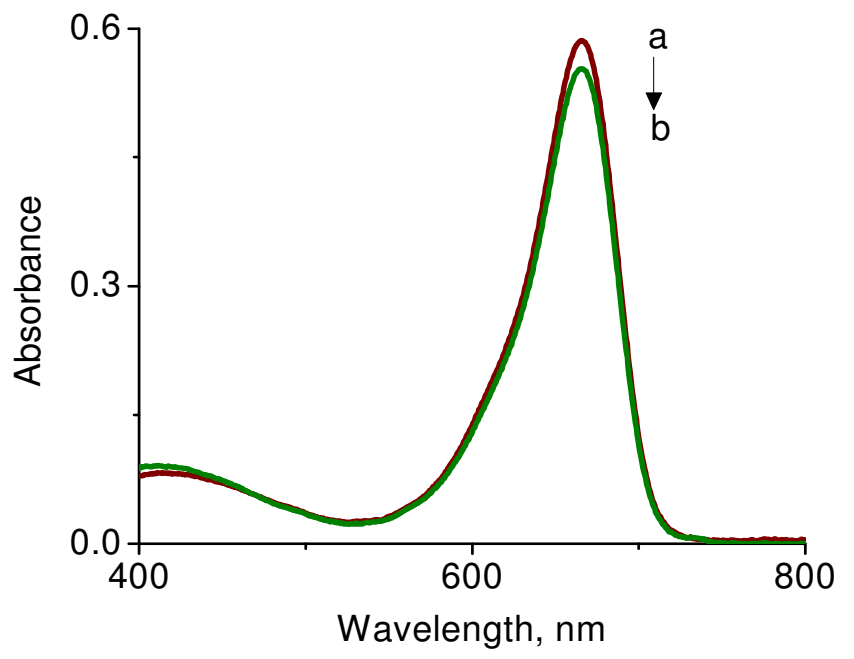

Figure S11. Changes in the absorption spectrum of $\mathbf{5 b}$ on continuous irradiation for $2 \mathrm{~h}$. 


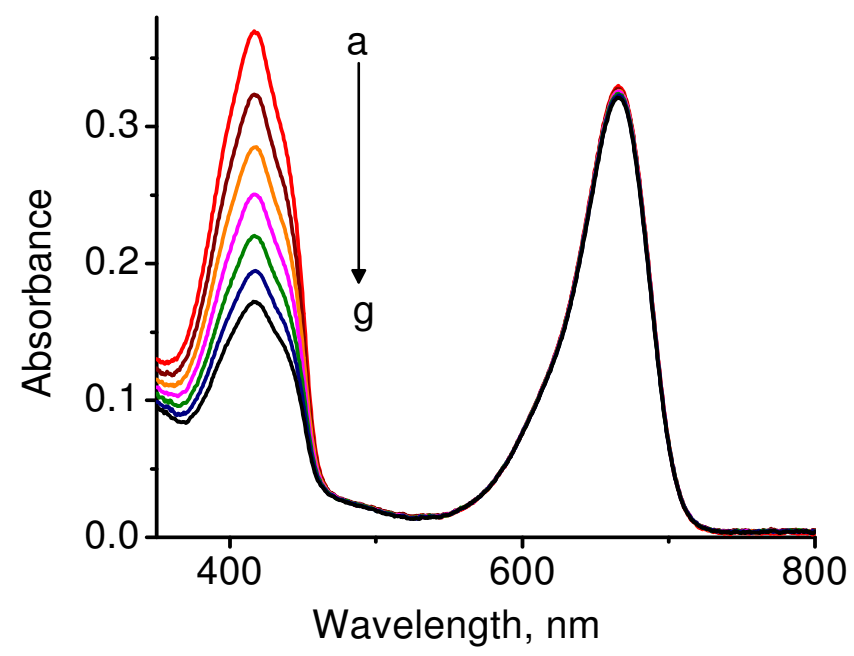

Figure S12. Changes in the absorption spectrum of DPBF upon irradiation in the presence of compound 5b in DMSO. a) 0 and g) $60 \mathrm{~s}$ (recorded at every $10 \mathrm{~s}$ intervals). 